\title{
Development of stress resistance of students of engineering universities during examination session by means of physical education
}

\author{
Rafael Khairullin ${ }^{1,3 *[0000-0001-8027-9854]}$, Olga Kalimullina ${ }^{2}$, Olga Salnicova ${ }^{1}$, Elena Bachenina ${ }^{1}$, \\ and Sergei Ilin ${ }^{1,3}$ \\ ${ }^{1}$ Kazan State University of Architecture and Engineering, 420043 Kazan, Russia \\ ${ }^{2}$ Volga Region State Academy of Physical Culture, Sport and Tourism, 420010 Kazan, Russia \\ ${ }^{3}$ Kazan State Institute of Culture, 420059 Kazan, Russia
}

\begin{abstract}
The article deals with the problem of stressful situations in learning activities and development of a person's stress resistance. The article investigates the conditions of stress resistance development of students by means of physical culture. In this aspect physical culture is considered as an integral quality of personality, as the condition and the premise of effective educational and professional activity, as the generalized indicator of professional culture of the future specialist and as the purpose of self-development and self-improvement.
\end{abstract}

Keywords. Physical education, stress, sport, physical culture, physical activity.

\section{Introduction}

Nowadays, there is a clear tendency observed in the educational process that every year there is more and more load on the intellectual, emotional and motivational spheres of a human being [1-5]. It should be noted that this specific activity is accompanied with quite complex morpho-functional changes in the human body, occurring against a background of significant physical and psycho-emotional stress.

It is known that in the process of studying at the university students' health significantly deteriorates: in some educational institutions the number of students related to the special medical group reaches $40 \%$ of the total number of students. A large number of academic disciplines and a significant time dedicated to independent work contribute to low physical activity and the emergence of various diseases. Cardiovascular and respiratory systems, musculoskeletal system diseases are of particular concern, i.e., diseases that affect the organs which functioning is the most important for human life, and every session the student gets involved into stress [6-9].

At the same time, the following issues are of particular interest to us: how and why stressful situations arise in educational activity and how to develop resilience to stressful situations. At present the phenomenon of students' stress tolerance in educational activity has not been studied well yet. The emergence of disharmonic and deforming components of

*Corresponding author: 89053146495@mail.ru 
stress, which negatively affect the quality of student's life and his/her becoming a professional, does not contribute to the development of stress resilience.

The research work was carried out on the basis of Kazan State University of Architecture and Engineering. The longitudinal experimental study involved 40 students aged 17-20.

We have selected a number of special physical exercises for university students, which they should perform immediately before examinations, on the free tension and relaxation of the main muscle groups [10-15]. A special feature of these exercises is that they alternate between strong muscular tension and subsequent relaxation [16-19]. Contraindications for performing the proposed exercises are diseases of the corresponding organs, and pathologies of the musculoskeletal system [20-24].

In order to relieve stressful conditions before exams and individual mastery of selfregulation techniques, one can perform a number of physical exercises such as «Lemon», «Balloon», «Fly» and «Ice Cream».

\section{Materials and methods}

The basic methodology of research included: the test of self-assessment of stress resistance S. Kouchen and G. Willianson [1]; a method of express diagnostics of stress level L. Reeder, and scales of psychological stress level (Kopina O.S.) for L. Reeder's test.

\section{Results}

The study was conducted in three stages.

The first stage (2018-2019) is theoretical. This stage was devoted to the choice of research methods, determining the relevance of the topic, the degree of study, the analysis of scientific literature related to the topic of research.

The second stage (2019-2020) is experimental. This stage included the development of the program of development of stress resistance among university students by means of physical culture. The experiment itself on diagnostics and formation of stress resistance of students during the examination session was conducted.

At the final, third stage (2020), we systematized and summarized all the results that we obtained during the research, mathematically processed the data of our experiment using Mann-Whitney U-test and Student's t-criterion. The statements and conclusions were formulated and clarified; the results of the study were formalized.

The novelty of our study and the results we obtained during the experiment are as follows:

1) it is proved that the development of stress resistance of the university student is a common concern for everyone;

2) systemic, personality-oriented approaches and theories of stress resistance development of university students are generalized at the theoretical and methodological level; the conceptual and terminological apparatus used in diagnostics and development of stress resistance of university students is specified and particularized;

3 ) the necessity of system-integrative approach to increase individual level of stress resistance of students has been substantiated; the criteria and indicators of stress resistance of university students have been determined;

The practical significance of the study lies in the possibility of applying the developed model and program in higher educational institutions to improve individual stress resistance of students as a major factor in optimizing learning activities and further successful professional adaptation. 


\section{Discussion}

Main conclusions of the research.

For a modern student stress is not something supernatural, but it is just a reaction of our body to all kinds of difficulties, which lead to psycho-emotional tension. This is especially true for the period when an exam session starts.

One of the most effective ways to combat stress is physical activity. There are many methods of dealing with stress, overcoming stress through sport is the most effective and simple way to change one's psychological balance with the help of exercise. Exercise and sports make up for the body's need for physical work. This is because doing physical activity increases efficiency and improves the health of a student. It is not necessary to perform any serious training, it will be enough to use the exercises we offer, but one of the main conditions is to perform them systematically.

In our experiment we studied the development of stress resistance of university students. At the ascertaining stage, the techniques chosen by us were offered to students in the control and experimental groups, students of these groups answered them according to the instructions offered by us. The obtained test data were processed, analyzed and systematized. Namely, we mathematically processed the data using Mann-Whitney $U$-test and Student's $t$-criterion. Having investigated the level of stress resistance with the help of «S. Kouchen and G. Williasson Self-Assessment Stress Tolerance Test» and stress level with the help of «L. Rieder Express Stress Level Diagnostics» we did not reveal any reliable differences between the two groups. Fig. 1-3 are shown in the form of a diagram. They demonstrate the data we obtained during the assessment of stress resistance and stress level in the control and experimental groups at the ascertaining stage of the experiment. The empirical values we received are in the zone of «insignificance». This suggests that there were no significant differences in the level of stress resistance and stress level between students in the control and experimental groups at the ascertaining stage.

After we conducted formative stage, in the course of which the shaping and developing methods are implemented, namely, we trained students of the experimental group with physical exercises, which they performed immediately before the exam. We made a control cut using the same methods as those at the ascertaining stage. We also processed the data mathematically using Mann-Whitney $U$-test and Student's $t$-criterion. Having investigated the level of stress resistance with the help of «S. Kouchen and G. Williasson's self-assessment stress test» and the stress level with the help of «L. Rieder Express Stress Level Diagnostics» we received empirical values which fell into the zone of «significance».

\section{Self-assessment of the stress resistance of the control group at the ascertaining stage}

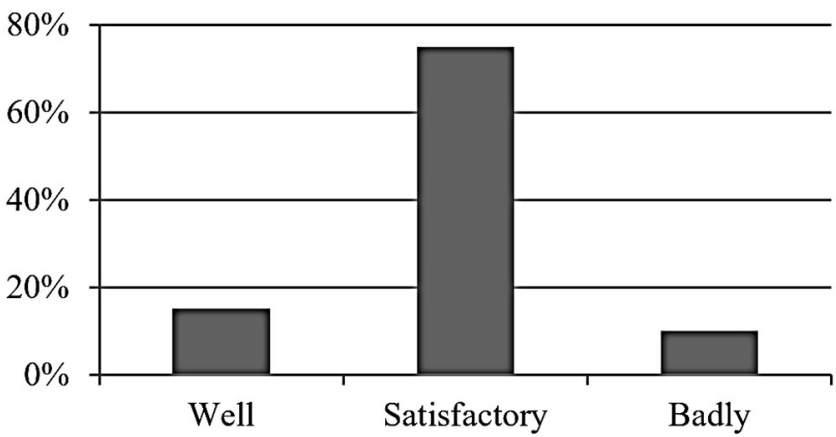

Fig. 1. Self-assessment of stress tolerance among students from control group at the ascertaining stage. 
Self-assessment of the stress resistance of the

experimental group at the ascertaining stage

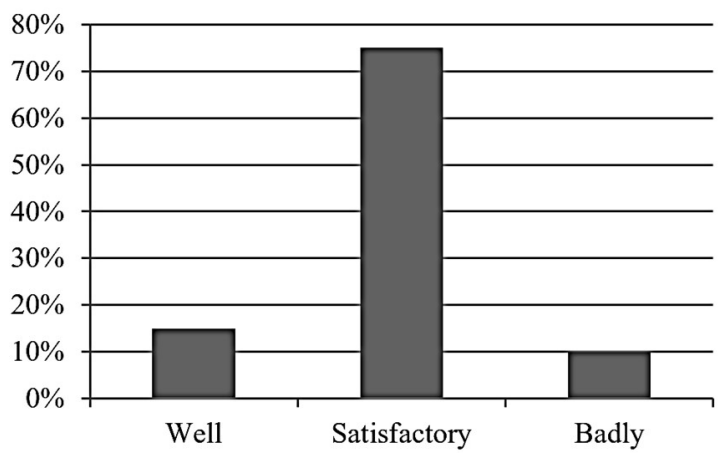

Fig. 2. Self-assessment of stress tolerance among students from experimental group at the ascertaining stage.

\section{Psychological stress level among students from control and experimental groups at the ascertaining stage}

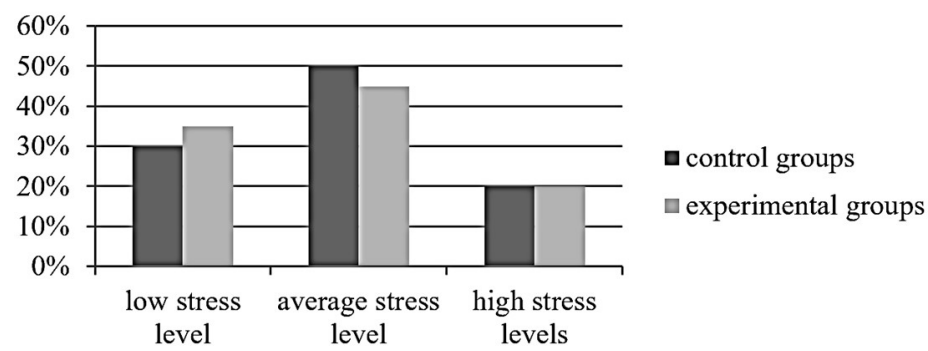

Fig. 3. Psychological stress level among students from control and experimental groups at the ascertaining stage.

This indicates that the stress level of the students in the experimental group decreased and stress tolerance increased. Fig. 4-5 show in the form of a diagram the data we received during the assessment of stress resistance and stress level at the control stage of the experiment in control and experimental groups.

\section{Self-assessment of stress tolerance among students in control and experimental groups (control assessment)}

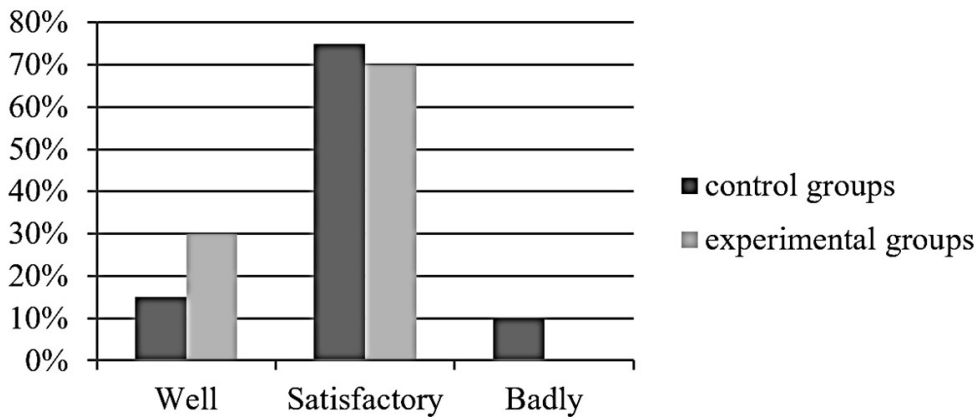

Fig. 4. Self-assessment of stress tolerance among students in control and experimental groups (control assessment). 


\section{Psychological stress level among students from control and experimental groups (control assessment)}

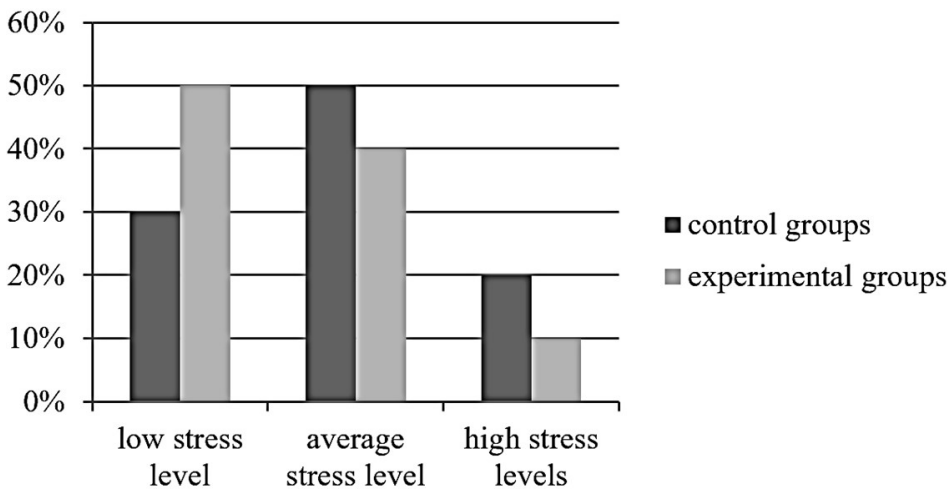

Fig. 5. Psychological stress level among students from control and experimental groups (control assessment).

\section{Conclusion}

We can draw the following conclusions:

- According to the results of «L. Rieder Express Stress Level Diagnostics» after conducting the experiment among university students, the level of stress in the experimental group decreased, which proves the effectiveness of our proposed physical exercises performed before the exams.

- According to the results of «S. Kouchen and G. Williasson's stress-resistance selfassessment test» after the experiment among university students, the students' selfassessment stress-resistance increased, which also indicates the effectiveness of our proposed physical exercises performed before exams.

The goal we set at the beginning of the study - to develop special means of physical culture to develop stress resistance of university students - has been achieved. We proved that students engaged in sports are more resistant to stress and recover from it faster than students who due to their health condition cannot systematically engage in physical activity. The hypothesis that the level of stress resistance among university students will increase if we choose effective physical exercises as the main means of physical culture to form stress resistance has been confirmed. Physical activity and sports may function as a universal remedy to increase health level, life expectancy and working age among the population, and also perform as efficient preventive of antisocial manifestations.

\section{References}

1. R.A. Khuzhin, A.V. Greb. Physical education service contribution to technical university graduate's professional competitiveness, Theory and Practice of Physical Culture 4, 12 (2019).

2. O. Kokun, Y. Imas, A. Vovkohon, V. Potop, G. Korobeynikov, L. Korobeynikova, A. Gorashchenco, A. Polevaya-Secaryanu. Physical education and sports as a tool for formation of psychophysiological readiness to their professional work, Journal of Physical Education and Sport 18 (2), 143, 966-971 (2018).

3. V. Panachev, L. Zelenin, A. Opletin, A. Legotkin, R. Kusekova. Aspects of healthimproving and sports-mass work students, Journal of Global Pharma Technology 10 (5), 268-273 (2018). 
4. L.G. Pashchenko, O.S. Krasnikova. Influence of motor mode on physical health of university students, Teoriya i Praktika Fizicheskoy Kultury 6, 24-26 (2017).

5. V.I. Filonenko, M.A. Nikulina, E.V. Patrakov, O.P. Kovtun. Social representation about health and health preservation in young students, Sotsiologicheskie Issledovaniya 7, 152-157 (2018).

6. F. Ishkineeva, K. Ozerova, S. Ahmetova, A. Kaveeva. Students' healthy lifestyle and the strategy of adaptation to the university environment, International Journal of Innovative Technology and Exploring Engineering 9 (1), 5123-26 (2019).

7. Resolution of the Government of the Russian Federation of 04.10.2000 N 751 «On the national doctrine of education in the Russian Federation» http://www.consultant.ru/ document/cons_doc_LAW_97368/(last accessed 2020/02/09).

8. N.K. Gafiatulina, L.I. Makadey, I.V. Gluzman, A.D. Lozhechkina, L.A. Volkova, A.P. Bandurin. The role of health-saving technologies in the process of students educational and professional socialization, EurAsian Journal of BioSciences 13 (2), 1557-63 (2019).

9. J.-H. Do, Y.-G. Jo, J.-S. Lim, C.-H. Yang. The motivation of physical education class in liberals arts participation, sports personality, and development of sociality in the university students, International Journal of Recent Technology and Engineering 82 Special Iss. 6, 208-214 (2019). DOI: 10.35940/ijrte.B1039.0782S619.

10. E. Koksalmiş, C. Garcia, G. Rabadi. The optimal exam experience: a timetabling approach to prevent student cheating and fatigue, International Journal of Operational Research 21 (3), 263-278 (2014). DOI: 10.1504/IJOR.2014.065408.

11. V.N. Irhin, I.V. Irhina, I.N. Nikulin. University sports and recreation activities system as a factor of ensuring the students health, World Journal of Medical Sciences 9 (3), 162166 (2013). DOI: 10.5829/idosi.wjms.2013.9.3.1131.

12. I. Bakiko, S. Savchuk, V. Dmitruk, O. Radchenko, S. Nikolaev. Assessment of the physical health of students of middle and upper grades, Journal of Physical Education and Sport 20 39, 286-290 (2020). DOI: 10.7752/jpes.2020.s1039.

13. Resolution of the Chief state sanitary doctor of the Russian Federation of 29.12.2010 N189 Moscow «on approval of SanPiN 2.4.2.2821-10» Sanitary and epidemiological requirements for the conditions and organization of education in General education institutions, http://nivanscool.ucoz.ru/dokument/novye_normy_sanpin_dlja_shkolnikov.htm (last accessed 2020/02/19).

14. V.R. Kuchma, L.M. Sukhareva, I.K. Rapoport, E.I. Shubochkina, N.A. Skoblina, O.Yu. Milushkina. Population health of children, risks to health and sanitary and epidemiological wellbeing of students: Problems, ways of solution and technology of the activity, Gigiena i Sanitariya 96 (10), 990-5 (2017). DOI: 10.18821/0016-9900-2017-9610-990-995.

15. B. Ewert. Promoting health in schools: Theoretical reflections on the settings approach versus nudge tactics, Social Theory and Health 15 (4), 430-447 (2017). DOI: 10.1057/s41285-017-0036-3.

16. T.H. Bailey, L.J. Phillips. The influence of motivation and adaptation on students'subjective well-being, meaning in life and academic performance, Higher Education Research and Development 35 (2), 201-216 (2016). DOI: 10.1080/07294360.2015.1087474.

17. L. Akshayaa, V. Vishnupriya, R. Gayathri. Awareness of chronic fatigue syndrome among the college students - a survey, Drug Invention Today 11 (6), 1369-71 (2019).

18. J. Shi, J. Shen, J. Xie, J. Zhi, Y. Xu. Chronic fatigue syndrome in Chinese middle-school students, Medicine (United States) 97 (4), 9716 (2018). DOI: 10.1097/MD.0000000000009716.

19. S. Griggs. Hope and mental health in young adult college students: An integrative review, Journal of Psychosocial Nursing and Mental Health Services 55 (2), 28-35 (2017). DOI: 10.3928/02793695-20170210-04. 
20. J.J.F. Breedvelt, Y. Amanvermez, M. Harrer, E. Karyotaki, S. Gilbody, C.L.H. Bockting, P. Cuijpers, D.D. Ebert. The effects of meditation, yoga, and mindfulness on depression, anxiety, and stress in tertiary education students, A meta-analysis Frontiers Psychiatry 10 (APR), 193 (2019). DOI: 10.3389/fpsyt.2019.00193.

21. J.D. de Vries, M.L. van Hooff, S.A. Geurts, M.A. Kompier. Exercise as an Intervention to Reduce Study-Related Fatigue among University Students, A Two-Arm Parallel Randomized Controlled Trial PloS one 11 (3), e0152137 (2016). DOI: 10.1371/journal.pone.0152137.

22. D.M. Nasibullina, T.R. Nasibullin, N.A. Krasulina. Individual academic physical education programs for special health groups for physical progress, Teoriya i Praktika Fizicheskoy Kultury 4, 54-56 (2019).

23. B. Butzer, M. Ebert, S. Telles, S.B. Khalsa. School-based Yoga Programs in the United States, A Survey Advances in mind-body medicine 29 (4), 18-26 (2015).

24. E. Yakimova, P. Terehov, O. Salnikova, N. Ishmuhametova. Crowdsourcing as an approach to solving environmental problems by future construction engineers, IOP Conference Series: Materials Science and Engineering 890 (1), (2020). DOI: $10.1088 / 1757-899 X / 890 / 1 / 01217$. 